\title{
PEMBINAAN MODEL PEMBERITAAN ISLAM DI MALAYSIA ${ }^{1}$ CONSTRUCTION OF ISLAMIC REPORTING MODEL IN MALAYSIA
}

\author{
Siti Suriani Othman \\ Fakulti Kepimpinan dan Pengurusan, \\ Universiti Sains Islam Malaysia \\ suriani@usim.edu.my \\ Lee Kuok Tiung \\ Fakulti Sains Sosial \& Kemanusiaan, \\ Universiti Malaysia Sabah \\ lee@ums.edu.my \\ Liana Mat Nayan, \\ Fakulti Industri Kreatif, \\ Universiti Tunku Abdul Rahman \\ liana@utar.edu.my
}

Tarikh dihantar: 20 Januari 2019 / Tarikh diterima: 5 April 2020

\begin{abstract}
Abstrak
Keperluan mengkaji proses sosial dalam konteks tempatan adalah penting termasuklah bidang komunikasi. Persoalan sama ada wujud keperluan menjana pengetahuan baharu mengikut konteks sesebuah negara yang mengambil kira norma dan budaya tempatan menjadi penting berikutan sebahagian besar pengetahuan dalam pelbagai bidang kajian hari ini lebih dekat dengan nilai-nilai Barat yang ada-kalanya dilihat tidak sensitif dengan nilai-nilai lokal. Dalam bidang kewartawanan, kajian empirikal dan penjelasan tentang proses pemberitaan khusus kepada sesebuah negara mula dipergiat untuk menjana pengetahuan yang mendalam tentang sesuatu proses tersebut. Dalam masa yang sama, wujud pandangan terhadap keperluan membina sesuatu model yang berlandaskan objektif dan nilai-nilai Islam meskipun ada juga pandangan yang sebaliknya. Idea ini timbul bukan atas dasar majoriti rakyat Malaysia beragama Islam tetapi berasaskan kepercayaan nilai-nilai murni yang dibawa dalam ajaran Islam boleh dijadikan prinsip asas kewartawanan. Dalam erti kata lain, penyepaduan dua sistem pendidikan untuk menggabungkan sistem pendidikan Islam dengan sekular untuk mengembangkan kurikulum yang lebih komprehensif dan moden. Dengan itu, kertas kerja ini cuba membincangkan kedua-dua pandangan, dengan menjuruskan perbincangan dan menghujahkan bahawa pengetahuan berbentuk lokal adalah lebih berguna dan bermakna dalam menggagahi pelbagai bentuk transformasi sosial dan perkembangan ilmu di abad 21 ini.
\end{abstract}

Kata Kunci: Islamization of Human Knowledge (IOHK), kajian kewartawanan, situated knowledge, komunikasi Islam.

Abstract: The need to study social processes in a local context is important including the field of communication. The question of whether there is a need to generate new knowledge according to the context of a country that takes into account of the local norms and culture becomes important as most knowledge in various fields of today's study is closer to Western values that are sometimes seen as insensitive to local values. In the field of journalism, empirical studies and explanations of the process of reporting specifically to a country are beginning to be intensified to generate in-depth knowledge of a process. At the same time, there is a view on the need to build a model based on Islamic objectives and values although there

\footnotetext{
${ }^{1}$ kertas ini telah dibentangkan dalam the International Conference on Social Sciences \& Humanities 2012 anjuran MENTION, Universiti Kebangsaan Malaysia pada 12-13 Disember 2012
} 
are also opposite views. This idea arose not on the basis of the majority of Malaysians being Muslims but based on the belief that the noble values brought in the teachings of Islam can be used as a basic principle of journalism. In other words, the integration of two education systems to combine the Islamic education system with the secular to develop a more comprehensive and modern curriculum. Thus, this paper attempts to discuss both views, by directing the discussion and arguing that local-shaped knowledge is more useful and meaningful in tackling various forms of social transformation and knowledge development in the 21 st century.

Keywords: Islamization of Human Knowledge (IOHK), journalism study, situated knowledge, Islamic communication.

\section{PENGENALAN}

Krisis identiti di kalangan masyarakat di dunia Islam terus berlaku, di mana salah satu punca ialah daripada laporan secara bias oleh media Barat terutama daripada segi kepercayaan dan amalan yang berbeza dengan pandangan mereka. Dalam persekitaran mediaskap baharu di Malaysia yang tiada sempadan hasil daripada globalisasi menyaksikan limpahan kandungan media saluran asing boleh diakses begitu mudah apatah lagi menerusi telefon pintar. Sukar menafikan sejak insiden 11 September (2001), media Barat dalam usaha mereka menangani terrorime telah menimbulkan islamophobia menjadikan Islam dan Muslim mangsa keadaan. Umat Islam sering dipaparkan sebagai 'berbeza' dengan masyarakat Barat, dan seterusnya 'kurang' dan 'konservatif' daripada segi kepercayaan dan amalan.

Keadaan ini boleh dikaitkan dengan kecenderungan pengkaji dari Timur mengkaji budaya Asia dengan teori Amerika (Miike 2003) dan akhirnya hanya tertumpu kepada mengaplikasi teori barat dan kurang melahirkan teori dari keadaan spesifik negara mereka (Gunaratne 2007). Hal ini pernah dikritik oleh Edward Said (1979) yang melihat kecenderungan masyarakat Timur (Orient) yang melihat diri mereka melalui kaca mata Barat (Occidentalis). Brian L. Massey dan Li-jing Chang (2002) mendapati kajian-kajian kewartawanan Asia banyak bertumpu kepada sub-rantau Asia Tenggara di samping terbatas atau menjurus kepada soal kebebasan akhbar.

Namun, isu media dan Islam itu sendiri kurang diberi perhatian oleh sarjana Islam kerana kebanyakan kajian hanya bertumpu kepada mengkaji institusi politik yang formal seperti parti politik, institusi diiktiraf kerajaan dan infrastruktur berkaitan kerajaan (Mowlana 1998), bukan kaitan antara Islam dan ajarannya dengan sistem komunikasi negara itu sendiri. Dalam konteks Malaysia pastinya lebih mencabar kerana rata-rata sering kali cuba melihat sesuatu isu sosial dari sudut politik. Seperkara lagi adalah sepertimana hujah Masterton (1996) iaitu apakah lebih mustahak mengenalpasti nilai-nilai kewartawanan sejagat yang terselindung dalam konteks Asia dan mempromosikannya sebagai suatu set nilai-nilai kewartawanan profesional yang diterima pakai oleh semua.

Keadaan serupa boleh dilihat wujud dalam senario pengkajian media di Malaysia, yakni sebuah negara sekular yang adakalanya diinterpretasikan sebagai sebuah negara Islam, yang mana penyelidik seperti Zaharom Nain (2000) berpendapat penyelidikan medianya lebih menjurus kepada isu yang berorientasikan media dan pengaruh politikal ekonomi di sebuah negara, berbanding isu proses pemberitaan sebenar (yang spesifik dan yang sebenarnya menentukan berita) (Siti Suriani Othman 2012) di sesebuah negara Islam itu. Kertas ini menghujahkan, pengkajian proses pemberitaan perlulah berlandaskan praktis sebenar yang diamalkan di sesebuah negara untuk mengelakkan daripada terjerumus ke arah penyelidikan yang dipengaruhi Barat dan mengabaikan keunikan budaya tempatan di mana berita diterbitkan. Cabarannya adalah pada melokalkan (localise) ilmu kewartawanan tersebut. 


\section{PENGARUH BARAT DALAM KAJIAN KEWARTAWANAN}

Ilmu kewartawanan di Malaysia berkiblat ke arah Barat. Sebahagian besar perintis-perintis sarjana komunikasi di Malaysia berlatar belakangkan pendidikan di UK mahupun Amerika Syarikat. Sesiapa yang berminat mengetahui lebih lanjut soal ini wajib baca penulisan Syed Arabi Idid (2014) yang mengupas soal ini dalam artikel beliau "The pas and coming communication jurney in Malaysia". Pengaruh barat dalam kajian kewartawanan dikaitkan dengan globalisasi. Penglobalisasian ini berlaku di pelbagai peringkat seperti di peringkat rantau dan antarabangsa. Di peringkat antarabangsa, penyelidikan kewartawanan banyak menggunakan teori barat untuk mengkaji keadaan di negara lain.

Kekuatan pengaruh barat dalam kajian kewartawanan telah banyak dibincangkan (Ma Rhea 2004, Papoutsaki 2007, Ray 2012, Thaman 2003, Tuhiwai Smith 2003). Dominasi ilmu barat ini berlaku kerana ia dilihat mampu memudahkan proses memahami kompleksiti kewartawanan di negara-negara membangun. Dengan itu, maka tidak hairan teori barat mula mendominasi perbincangan tentang dunia timur yang jauh lebih berbeza, selain struktur pelajaran Amerika yang pertama sekali memasukkan kewartawanan dan pengkajian media dalam peringkat yang lebih tinggi dan kemudiannya menjadi satu bentuk hegemomi Amerika ke atas negara-negara lain (Papoutsaki 2007).

Masalah ini telah mendapat kritikan daripada sarjana Timur, iaitu dari segi adaptasi teori barat yang dilihat tidak kritikal, negatif dan pasif serta berbentuk sehala (dari Barat ke Timur). Kecenderungan mempromosi dan meniru berita yang disiarkan Barat dan dilihat sebagai satu bentuk universal, telah diterima oleh sesetengah negara yang kononnya menekankan demokrasi. Peniruan ini, tanpa melihat kesesuaiannya telah menyebabkan kekeliruan. Misalnya, konsep watchdog di barat melahirkan media yang menentang kerajaan, di mana keadaannya mungkin berbeza bagi negara-negara membangun yang perlukan media untuk bersama-sama kerajaan dalam menyokong proses pembangunan (Hamilton 1999). Hal ini juga membawa kepada sarjana seperti Mughal MJ dan Ali MM. (2015) membincangkan apa yang dikenali sebagai pengislaman pengetahuan manusia atau lebih dikenali sebagai Islamization of Human Knowledge (IOHK).

IOHK melihat pengetahuan moden kontemporari sebagai "kandungan dan tafsiran" yang tercipta berasaskan pada pandangan dunia sekular Barat, sehingga ia menyebabkan deIslamisasi (sekularisasi) pemikiran umat Islam. Hal ini mengingatkan kita bahawa model barat tidak semestinya sesuai dengan keadaan timur dan tidak universal sifatnya, yang menjadi thesis awal buku tulisan Hallin dan Manchini (2004) berjudul Comparing Media Systems: Three Models of Media and Politics. Tambahan lagi, pengkajian kewartawanan di negara-negara berbeza itu sendiri adalah fenomena yang sangat unik antara satu pengalaman dengan satu yang lain (De Beer 2009). Usaha ini adalah untuk mengelakkan apa yang diperhatikan oleh Chen dan Miike (2006) di mana sarjana Timur sendiri tidak dapat menginterpretasi fenomana di negara mereka sendiri kerana kurang kefahaman tentang warisan budaya mereka yang berbeza dengan Barat.

Selain mengutamakan keunikan ciri-ciri tempatan, pengkaji Timur juga digesa untuk mengkaji bidang media dengan memasukkan unsur Islam di dalam pengkajian (Semati 2011) sebagai salah satu unsur tempatan. Walau bagaimanapun, pengkajian sebegini, hujah Semati lagi, penyelidikan yang mengkaji dari aspek agama juga harus mengelakkan daripada perangkap generalisasi dan universaliti agama. Kajian begini, dilihat kurang sesuai untuk digelar sebagai pengkajian media 'dari perspektif Islam'. Ini kerana,

It is far more difficult to identify something called "an Islamic point of view". Acknowledging the diversity of contexts in which "Islam" and various practices attributed to it in various national, cultural, and societal configurations makes any such perspevtive impossible to emerge. Identifying such a perspective is difficult event at a national level, let alone a global level (Semati 2011: 115). 
Misalnya, Semati mengambil contoh negara Iran, Afrika Selatan dan Timur Tengah, bagaimana negara dan benua-benua ini sangat berbeza daripada segi praktis Islamnya, dan pastinya amat sukar untuk menyediakan penjelasan yang bersifat generalisasi kepada keadaan yang amat berbeza ini.

Buat masa ini, kajian media di Malaysia boleh disifatkan dipengaruhi oleh pandangan barat misalnya teori politikal ekonomi. Hal ini tidak salah, tetapi yang menjadi masalahnya ialah apabila teori-teori ini mempunyai kecenderungan mengeneralisasikan temuan kajian sehingga memberi implikasi seolah-olah sesetengah negara yang mempunyai persamaan daripada segi tadbiran politik misalnya, akan mempunyai persamaan yang boleh dijangka (lihat Hallin dan Manchini 2004).

Keadaan ini juga boleh dikaitkan dengan kecenderungan pengkaji dari Timur mengkaji budaya Asia dengan teori Amerika (Miike 2003) dan akhirnya hanya tertumpu kepada mengaplikasi teori barat dan kurang melahirkan teori dari keadaan spesifik negara mereka (Gunaratne 2007). Hal inilah yang dikritik oleh Edward Said (1979) sebagaimana yang disebutkan tadi.

Kritikan ini membuatkan kita terpanggil untuk meneliti adakah usaha seperti 'Nilai Asia' (Asian Values) yang dikaitkan dengan Kewartawanan Asia (Asian Journalism) yang merupakan usaha mengelakkan diri daripada digeneralisasi oleh teori media dari Barat. Namun, definisi Nilai Asia itu sendiri masih kabur dan masih terjerumus dalam konsep generalisasi di kalangan negara-negara Asia sendiri.

Hakikatnya, Nilai Asia yang diamalkan di negara-negara Asia adalah berbeza. Misalnya Nilai Asia di Malaysia dikaitkan dengan unsur Islam, berbanding Singapura yang lebih berorientasikan ajaran Confucious (Xu 2005). Justeru, di sini kita berbalik kepada isu generalisasi penteorian komunikasi Mowlana (1996) yang dikritik Khiabany (2003) yang memerlukan penteorian lebih spesifik dan menghargai keunikan sistem dan amalan di sesebuah negara. Konsep Nilai Asia itu sendiri adalah silap jika turut digeneralisasikan kepada seluruh benua Asia tanpa meraikan perbezaan antara setiap negara yang mengamalkannya (Siti Suriani Othman 2012).

Selain itu, pendekatan lain yang digunakan ialah dengan de-westernize ('pentimuran') pengetahuan sebagaimana dilakukan oleh sarjana yang dikenali dengan usaha ini seperti Curran dan Park (2000), Papoutsaki (2007) dan Wasserman dan de Beer (2009), manakala antara perbincangan lain yang terkini dihasilkan ialah tulisan Shelton Gunaratne (2010), sungguhpun Tapas Ray (2012) menangkis pandangan Gunaratne dan menghujahkan kekuatan teori barat masih penting untuk memahami konteks timur.

Curran dan Park (2000) misalnya, dalam buku mereka De-Westernizing Media Studies ada membincangkan konsep ini dari perspektif Malaysia, misalnya melalui tulisan Zaharom Nain dalam bab bertajuk "Globalized Theories and National Controls: TheState, theMarket, and the Malaysian Media". Gunaratne (2010) pula yang banyak menyokong pandangan Syed Farid Alatas dalam bukunya Alternative Discourse in Asian Social Science melihat kurangnya penjanaan ilmu sosial sains konteks Asia yang dibuat untuk mencapai konsep-konsep dan teori tersendiri dan kaedah kajian yang inovatif. Dalam buku itu, Syed Farid memerhati bahawa kebanyakannya, ilmu barat digunakan secara membuta tuli oleh pengkaji dari Timur. Gunaratne (2010: 477-479) pula menambah, beberapa masalah utama dalam mengeneralisasikan pengkajian sains sosial termasuklah, antara yang utama:

1. Orientalisme - pandangan Barat yang digunakan untuk memahami perlakuan sosial masyarakat Timur.

2. Eurosentrisme - pandangan bahawa orang Eropah adalah unik dan lebih penting daripada bangsa lain di dunia.

Pandangan seperti ini adalah contoh bagaimana dominasi pengkajian Barat menguasai ilmu kewartawanan berterusan. Antara langkah yang boleh diambil ialah dengan 
mencadangkan pengkaji unntuk menjalankan kajian berbentuk kualitatif seperti melalui kaedah pemerhatian untuk memahami praktis sebenar wartawan di negara yang terlibat (Papoutsaki 2007). Di sinilah, sepatutnya boleh dijadikan landasan untuk membina model pemberitaan sesebuah negara yang berlandaskan praktis kewartawanan.

\title{
MODEL PEMBERITAAN DI NEGARA ISLAM DAN KRITIKAN
}

Memang ada cubaan untuk mendefinisikan apa yang dimaksudkan sebagai komunikasi Islam seperti oleh Muhammad Kamil al-Din Ali Yusuf iaitu "satu perbuatan menyebarkan maklumat [maklumat, idea dan sikap] benar dan tepat berdasarkan pandangan Islam (dipetik dalam Zulkiple Abd Ghani dan Mohd Safar Hasim 2004: 62). Pendefinisian model yang berkaitan Islam sering dikaitkan dengan konsep tauhid iaitu konsep Allah yang satu yang menjadi asas niat dan kesan daripada komunikasi yang dihasilkan. Dalam usaha ini, elemen komunikasi yang terpenting ialah melaporkan maklumat yang benar, objektif dan tepat kepada khalayak. Kebenaran, sebagaimana yang dibincangkan oleh Imam al-Ghazali,

\begin{abstract}
“...has a wider connotation as it must present in speech, in intention, in resolution, in the fulfillment of resolution, in action and in all the stations on the path. He [Ghazali] truthfulness with intention and sincerity, the three virtues for him are inseparable because intention is a basic requirement of devotional acts, intention without sincerity will produce harmful to the soul, and sincerity without truthfulness is obviously in vain. He maintains that good intention will create truthfulness to God and a firm determination for good deeds"(dalam Zulkiple Abd Ghani dan Mohd Safar Hasim 2004: 66).
\end{abstract}

Secara umumnya, proses pemberitaan di sesebuah negara Islam diteorikan oleh Hamid Mowlana (1996) melalui model komunikasi Islam yang berbeza dengan model-model di Barat dan menumpukan negara Islam sebagai negara yang 'takut kepada Tuhan', serta berdasarkan Quran, Sunnah dan Syariah. Mowlana (1989b) menegaskan bahawa dalam sistem komunikasi Islam perlu wujud rasa takut kepada Allah yang satu atau konsep tauhid yang disebutkan tadi, perasaan untuk menerbitkan hasil media yang bertanggungjawab dan boleh membimbing khalayaknya, konsep tabligh dan prinsip takwa iaitu takutkan Allah.

Mowlana adalah antara sarjana yang tegar berpendirian bahawa sistem media di Iran sebagai "melaksanakan fungsi utamanya, yang dikawal oleh negara Islam, iaitu tabligh atau menyampaikan" (Mowlana 1989: 38). Dalam penyebaran maklumat dalam sebuah negara Islam, Mowlana (1989b) juga menambah wujud perbezaan antara propaganda dan sistem komunikasi Islam ialah propaganda tidak perlukan agama untuk dilaksanakan.

Namun, walaupun model oleh Mowlana ini amat berpengaruh dalam memahami sistem komunikasi dari luar kaca mata Barat, model ini dikritik Khiabany (2003) kerana mengabaikan hakikat bahawa sesebuah negara Islam yang spesifik tidak boleh digeneralisasi proses komunikasinya dengan sebuah negara Islam yang lain. Hal ini jelas, menurut Khiabany kerana model komunikasi Islam Mowlana hanya berlandaskan pengalaman Iran dan bukan negaranegara Islam lain secara menyeluruh. Makanya, tidak boleh buat generalisasi atau sama-ratakan semuanya.

Kami bersetuju dengan pandangan Khiabany ini, dan berpendapat bahawa usaha mengeneralisasi model komunikasi yang berpaksi di negara Iran, misalnya, ke sesebuah negara lain, adalah usaha yang sesuai disifatkan sebagai 'banal communitarianism' (Khiabany 2003: 417). Ini kerana, generalisasi sedemikian rupa adalah kurang tepat kerana setiap negara itu berbeza dari segi budaya tempatan masing-masing. Malah, mana-mana negara di Dunia itu sendiri wujud sistem atau golongan minoriti yang berbeza dengan sistem arus perdana. Tambahan lagi, dalam konteks Malaysia, sebarang bentuk pengeneralisasian walaupun dalam konteks Malaysia yang dihuni pelbagai bangsa adalah kurang tepat. 
Dalam konteks pengoperasian konstruk, Hamid Mowlana (1996) juga dikritik kerana melihat 'Islam' dalam bentuk 'model monolitik' iaitu sebagai 'satu agama yang melahirkan satu masyarakat yang serupa', sedangkan tidak wujud masyarakat Islam yang 'sama' di manamana bahagian di dunia ini (dan hal ini dikaitkan dengan perbezaan budaya) dan gagal melihat perbezaan yang wujud antara struktur agama, organisasi, tradisi dan sekolah yang bukan hanya berlaku antara masyarakat berbeza malah di dalam satu-satu masyarakat tertentu itu (Khiabany 2003: 416). Menurut Khiabany, inilah yang dikatakan sebagai usaha yang cuba mengeneraliasi 'negara' kepada 'budaya'.

Selain itu, model ini juga dikritik kerana dengan mudahnya melabel kerajaan Iran sebagai sebuah negara yang melaksanakan "komunikasi Islam", sedangkan, sebagaimana dihujah Semati (2011), jika contoh Mowlana (1979) dalam menerangkan model komunikasi Islamnya ialah daripada segi pengoperasian dan siaran Islamic Republic of Iran Broadcasting (IRIB) sebagai contoh pusat penyiaran yang berbentuk Islam dan menyiarkan elemen Islam di dalamnya, Semati melihat hal ini tidak 'seIslam' yang dijelaskan Mowlana kerana “IRIB sering menyiarkan musik pop yang tidak boleh diterima dari segi bentuk dan isi kandungan, terutama sejak beberapa tahun kebelakangan ini" (Semati 2011: 117). Di sini, muzik pop yang diistilahlah sebagai Islam menjadi semakin tidak bermakna kerana hampir semua bentuk muzik dikatakan sebagai Islam. Hal ini yang digelar sebagai "essentialzing "Islam" dan "masyarakat Islam" kerana dengan mudahnya melihat operasi media sebagai Islam jika ia beroperasi dalam negara Islam (Semati 2011: 123).

Misalnya, dalam konteks mengkaji filem Malaysia, filem seperti Syurga Cinta terbitan David Teoh, serta Mualaf, sebuah filem Yasmin Ahmad boleh dijadikan contoh bagaimana unsur Islam ada dimasukkan tetapi tidak sampai kepada mesej sebenar. Dalam kajian analisis kandungan kualitatif, Rosmawati Mohamad Rasit et al (2011) menyimpulkan bahawa keduadua filem gagal menyampaikan mesej dakwah sepenuhnya kerana antaranya, gaya hidup barat yang dipaparkan di awal filem Syurga Cinta, dan unsur liberalisme dan pluralisme dalam filem Mualaf. Menurut pengkaji, filem-filem ini masih belum berupaya mendebatkan nilai keagamaan yang sebenar kerana bercampur aduk dengan elemen yang tidak selari dengan ajaran Islam. Dalam contoh ini, sungguhpun mudah untuk media di Malaysia yang mengandungi unsur Islam dikategorikan sebagai contoh produk media Islam, namun hakikatnya pendefinisian sebenar tidaklah semudah itu. Ini membawa kepada keperluan untuk pengkaji menteori komunikasi di negara Islam dengan mengambil kira saranan Semati (2011) yang menyarankan agar pengkajian aspek Islam dalam penyelidikan media perlulah ditunjangi daripada ajaran sebenar dan bukannya 'ditempel' dengan 'perspektif Islam' semata mata, di samping menekankan pengkhususan dalam pengkajian kewartawanan.

Di samping semua ini, kita tidak boleh lupa soal metodologi apabila berbicara pasal pembangunan ilmu baharu. Louay Safi (1996) telah lama membicarakan keperluan suatu metodologi yang lebih praktikal, saintifik, dan komprehensif. Hujah beliau IOHK perlulah inklusif melibatkan kedua-dua kaedah Muslim Klasik dan Moden Barat sesuai dengan relevan masa kini.

\section{KEPENTINGAN MENGKAJI PERLAKUAN SOSIAL MELALUI PENGKHUSUSAN} (SPECIFICITY)

Kajian bagi tujuan menempatkan secara empirical nilai-nilai Asia dalam kewartawanan Asia sudah lama dibincangkan dan kemuncaknya adalah pada 1990-an oleh sarjana-sarjana dari Barat dan Asia sendiri (seperti Bublie \& Sitaraman, 1998; Elliott, 1998, Chang, Wang, \& Chen, 1998; Ha, 1994; Zhu, Weaver, Lo, Chen, \& Wu, 1997). Nilai-nilai Asia pada dasarnya didefinisikan sebagai idea daripada identiti perkongsian dan serantau yang dibentuk daripada kepercayaan teras yang unik kepada satu rantau yang besar yang pada hakikatnya berbeza-beza dilihat dari kebanyakan sudut-sudut lain. Ini yang menyebabkan sarjana seperti Xu (1998) 
memberi pandangan nilai-nilai Asian tersebut adalah kontroversial. Apa tidaknya, jika rantau Asia itu sendiri begitu besar dengan sistem kerajaan dan budaya yang begitu unik. Malaysia sendiri merupakan sebuah negara yang unik dengan masyarakat pluralistinya yang berbilang kaum dan tidak lupa Australia itu turut tergolong dalam kontinen Asia.

Dalam perbincangan tentang menjana pengetahuan berbentuk Timur, Gunaratne (2010) menerangkan kepentingannya, dengan mengambil kira tulisan Yasuko Ito, sarjana Jepun yang pernah menyatakan:

\begin{abstract}
There are many social theories, including widely accepted theories, [which] do not explain the Japanese experience at all. Yet there are other social theories developed outside Japan that explain the Japanese experience quite well. Furthermore, there are social theories that explain Western and Japanese experiences very well but do not explain the experiences of Third World countries. In this sense, social science theories, unlike natural science theories, are culturally bound. Many social theories reflect cultural norms, biases and other characteristics.
\end{abstract}

Daripada kejayaan Jepun mengkaji sains sosial melalui perspektifnya yang tersendiri, Gunaratne menyarankan agar model bipolar (iaitu model barat yang berguna diaplikasi dalam konteks Jepun, manakala teori berasaskan tempatan juga dijana daripada kajian-kajian empirikal) yang digunakan di Jepun boleh diaplikasikan di bahagian lain di Asia. Model ini, tambah Gunaratne, boleh diperbaiki, dari aspek (1) menimba ilmu falsafah dan sorotan literatur bersifat tempatan untuk mendapatkan idea untuk menghasilkan 'model komunikasi tempatan', (2) menghasilkan teori komprehensif daripada teori sistem, (3) memulakan penghasilan jurnal berwasit, lebih baik jika mempunyai akses secara atas talian, dan penerbitan buku di peringkat universiti yang beroperasi selain daripada Barat, (4) menulis buku teks dalam bahasa Inggeris dan bahasa-bahasa lain seperti bahasa Cina, Melayu, Indonesia dan Hindu/Urdu yang menekankan pemikiran sosial di kalangan sarjana Timur di peringkat ASEAN atau mana-mana peringkat yang bukan barat.

Usaha 'mentimurkan' ilmu dalam sesebuah bidang pengajian ialah contoh sebagai apa yang dipanggil 'ilmu terletak' atau situated knowledge yang melihat setiap ilmu adalah berasal daripada sesuatu 'tempat'. Justeru, pengkaji di Timur harus cuba mengelakkan daripada terus menghasilkan ilmu terhasil bersumberkan konteks yang khusus (De Beer 2009). De Beer menggunakan contoh Afrika Selatan dalam mengilustrasikan bagaimana ilmu kewartawanan harus berpunca daripada ilmu tempatan berbanding mengaplikasikan ilmu barat.

Dalam mencapai hasrat ini, De Beer juga mencadangkan beberapa peringkat yang perlu dilalui oleh 'ilmu' untuk mentimurkannya iaitu dengan (1) mengenalpasti ketidakseimbangan dalam ilmu kewartawanan dan hal ini berkait rapat dengan espistemologi (punca ilmu) yang umumnya melihat berlakunya generalisasi atau universaliti terhadap ilmu kewartawanan. Curran dan Park (2000) melihat generalisasi seperti ini tidak adil kepada keseluruhan korpus ilmu dalam bidang kewartawanan kerana ianya hanya dikuasai oleh beberapa negara Barat sahaja.

Dalam hal yang sama, pendekatan hampir sama diutarakan oleh Profesor Donna Haraway (1991) yang merupakan seorang penteori feminis tersohor, yang dipanggil sebagai situated knowledge. Yang utama dalam pendekatan yang boleh diaplikasi dalam kajian media ialah mengelakkan mengeneralisasikan pengkajian media kepada media lain. Konsep ini sebenarnya lahir daripada idea bahawa dalam budaya menghasilkan penemuan dan pengetahuan sains, wujud prejudis terhadap maskuliniti. Melalui situated knowledge, Haraway menyarankan penglibatan feminis dalam budaya maskulin tersebut.

Kelebihan pendekatan ini ialah dapat mengelakkan objektiviti sains dengan lebih mendalam kerana pengkajian sains selama ini dipengaruhi oleh masalah reductionism, yang antara lain berkaitan dengan cubaan mengeneralisasi penemuan kajian dalam konteks yang 
lain. Justeru, objektiviti sains dalam konteks feminis adalah berkaitan dengan "lokasi terhad" (limited location) dan 'situated knowledge' yang menentang penjanaan ilmu yang tidak mempunyai 'lokasi' tertentu di mana ia dilihat sebagai tidak bertanggungjawab.

Misalnya, pendekatan Actor Network Theory yang diperkenalkan ahli falsafah Burno Latour boleh dikaitkan dengan idea Haraway ini dari segi spesifisiti penjanaan ilmu yang sangat khusus lokasinya iaitu di dalam makmal sains (Latour 1987, Latour dan Woolgar 1979). Dengan kata lain, objektiviti sains dicapai melalui pandangan daripada sesuatu tempat yang khusus.

Dalam konteks feminisme, Haraway (1988) mengajak pengkaji feminis supaya tidak mengharapkan pengkajian berbentuk humanis dan positivis untuk menerangkan tentang feminism, tetapi mereka harus mempunyai cara tersendiri untuk memahami feminisme secara khusus - iaitu dengan cara mereka sendiri untuk bercakap tentang realiti feminis. Untuk mencapai ini, Haraway menambah "partiality and not universality is the condition of being heard to make rational knowledge claims" Haraway 1988: 589) yang, Haraway menambah, "only partial perspective promises objective vision... Feminist objectivity is about limited location and situated knowledge, not about transcendence and splitting of subject and object" (Haraway 1988: 583). Justeru, dalam usaha menjana ilmu empirikal yang sedimikian rupa, Haraway percaya bahawa praktis tempatan ialah jawapan bagi memahami sesuatu perlakuan sosial.

Justeru, kertas ini menyokong penggunaan konsep 'specificity' atau 'situated knowledge' yang dicadangkan Haraway (1991) di mana Haraway menolak pembentukan teori yang bersifat umum kerana ia adalah 'kesalahan paling besar [dalam dunia penyelidikan akademik] kerana mengabaikan realiti' (Haraway 1991). Apatah lagi, dalam banyak-banyak institusi yang wujud di dunia ini, 'bidang pendidikan dan penyelidikan adalah bidang yang paling banyak berdasarkan teori barat" (Wang 2011).

Khusus kepada keperluan mengkaji akhbar di negara Islam, hal ini juga berkait rapat dengan kritikan Khiabany (2003) terhadap Mowlana yang mengkaji sistem komunikasi di Iran untuk menjana model komunikasi Islam, tetapi mengabaikan peranan mesej hiburan dalam masyarakat. Di sini, Khiabany melihat kandungan hiburan sebagai satu perbincangan penting dalam memahami komunikasi dalam sesebuah negara Islam dan tidak boleh diabaikan. Justeru, asas pembinaan model pemberitaan di yang perlu dibina perlu juga mengambil kira unsur hiburan dalam pembinaan model tersebut.

\section{KESIMPULAN}

Kesimpulan daripada perbincangan ini ialah, wujud keperluan untuk pengkajian kewartawanan dibuat dalam konteks lokal sesebuah negara yang berkaitan, dan untuk 'mengenali' kewartawanan secara spesifik itu, pendekatan situated knowledge boleh digunakan. Bukan bermaksud pengislaman ilmu atau islamisasi ilmu tetapi atas kepercayaan objektif dan nilainilai Islam boleh diserap masuk dalam ilmu sains sosial, kemanusiaan atau lain-lain cabang ilmu pengetahuan. Melalui kaedah ini, yang diutamakan dalam penyelidikan ialah praktis yang diamalkan oleh jurnalis dalam menghasilkan produk media. Di sini, kekuatannya ialah berupaya memahami sesuatu amalan kewartawanan bukan berlandaskan 'andaian' sematamata sebagaimana yang sering dilakukan melalui pendekatan politikal ekonomi, pengkajian budaya dan pendekatan organisasi. Sungguhpun setiap pendekatan ini telah banyak melahirkan ilmu tentang kewartawanan dan sumbangannya tidak disangkal, tetapi telah tiba masanya untuk penyelidikan yang bersumberkan praktis dikaji demi menyahut cabaran melahirkan ilmu yang bersifat tempatan.

Justeru persoalan sama ada wujud keperluan untuk mewujudkan model pemberitaan Islam boleh dilihat sebagai satu usaha ke arah mewujudkan ilmu yang berbentuk sedemikian. Namun, terdapat beberapa faktor yang perlu diambil kira dalam menghasilkan model yang 
sedemikian, kerana dikhuatiri bahawa model ini hanya menjadi satu bentuk yang essentialised Islam (Semati 2011) dan tidak menggambarkan keadaan pelbagai bangsa dan agama di Malaysia. Justeru, cadangan bagi menghasilkan model yang dimaksudkan mestilah mengambil kira:

1. Spesifisiti ilmu yang akan dihasilkan, iaitu, penemuan kajian bukan hanya berkontekskan tempatan tetapi juga praktis tempatan.

2. Konteks sosial negara di mana ilmu dihasilkan (contoh: kepelbagaian bangsa dan agama)

3. Mengelakkan kecenderungan untuk essentialise Islam walaupun mengkaji sistem media di Malaysia.

4. Mengkaji unsur hiburan dan peranan serta kesannya dalam sistem komunikasi sesebuah negara yang dikaitkan dengan Islam.

Sehubungan itu, makalah ini mencadangkan agar model pembinaan berita di Malaysia perlu dihasilkan, tetapi kajian perlu merangkumi akhbar-akhbar berbahasa Cina dan India, selain akhbar berbahasa Melayu dan Inggeris. Unsur Islam perlu dikaji dalam bentuk yang disarankan oleh ajaran Islam, tanpa jatuh kepada sebarang bentuk generalisasi seperti pengoperasian media di sebuah negara Islam. Usaha ini merupakan langkah penting untuk memahami kewartawanan dalam bentuk lokal, di samping menyahut cabaran transformasi sosial pengetahuan di abad ke-21 ini.

\section{RUJUKAN:}

Brian L. Massey \& Li-Jing Chang (2002). Locating Asian Values in Asian Journalism: A Content Analysis of Web Newspapers. Journal of Communication, 52(4), 987 - 1003. DOI: $10.1111 / \mathrm{j} .1460-2466.2002 . t b 02585 . \mathrm{x}$

Chen, G. M., \& Miike, Y., (2006). The ferment and future of communication studies in Asia: Chinese and Japanese perspectives. China Media Research, (1), 1-12.

Curran, J., \& Park, M., (2000). De-Westernizing Media Studies. London: Routledge.

Foley, M. (2010). The Press and Democracy Building: Journalism Education and Training in Eastern and South-Eastern Europe during Transition. Masters dissertation. Technological University Dublin. doi:10.21427/D7QK77

Gunaratne, S. A., (2007). Let many journalism bloom: Cosmology, orientalism and freedom. China Media Research, 3(4), 60-73.

Gunaratne, S., (2010). De-westernizing communication/social science research: Opportunities and limitations. Media Culture \& Society. 32 (2): 473-500.

Hallin, D.C., \& Manchini, P. (2004). Comparing Media Systems: Three Models of Media and Politics. Cambridge, UK: Cambridge University Press.

Haraway, D., (1991). Simians, cyborgs and the women: the reinvention of nature. London: Free Association.

Haraway, D., (1988). Situated Knowledge: The science question in feminism and the priviledge of partial perspective. Feminist Studies, 14(3), 575-599.

Haraway, D., (1991). Simians, cyborgs and the women: the reinvention of nature. London: Free Association.

Hamilton, J., (1999). Lessons for the media from foreign aid, journalists in newly democratic countries mush chart their own course. Media Studies Journal 98-105.

Khiabany, G., (2003). De-westernizing media theory, or reverse orientalism: 'Islam Communication' as theoriezed by Hamid Mowlana. Media Culture Society, 25, 415422.

Latour, B., (1987). Science in action. Milton Keynes: Open University Press.

Latour, B., \& Woolgar, S., (1979). Laboratory life: the social construction of scientific facts. Beverly Hills; London: Sage Publication. 
Louay Safi., (1996). The Foundation of Knowledge: A Comparative Study in Islamic and Western Methods of Inquiry.

Ma Rhea, Z., (2004), The preservation and maintenance of the knowledge of indigenous peoples and local communities: the role of education. Paper presented at the AARE Conference, Melbourne.

Maslog, C. (1996). Values: Idle concept or realistic goal? In M. Masterton (Ed.), Asian values in journalism (pp. 140-147). Singapore: Asian Media, Information, and Communication Centre.

Masterton, M. (Ed.). (1996). Asian values in journalism. Singapore: Asian Media, Information, and Communication Centre.

Miike, Y., (2003). Beyond Eurocentrism in the intercultural field: Searching for an Asiacentric paradigm. In STAROSTA, W. J., and CHEN, G. M., eds., Ferment in the intercultural field: Axiology/value/praxis. Thousand Oaks, CA: Sage.

Mowlana, H., (1996). Global communication in transiton: The end of diversity? Thousand Oaks, CA: Sage.

Mowlana, H., (1998). Covering Islam: The media and its mpact on Muslim identity. International Conference on Muslim Identity in the 21st century: Challenges of modernity?, School of Oriental and African Studies University of London, October 31November 11998.

Mowlana, H., (1989a). The Islamization of Iranian television. Intermedia, 17(5), 35-39.

Mowlana, H., (1989b). Communication and cultural settings: An Islamic perspective. The Bulleting of the Institute of Communications Research, Keio University, Japan.

Mughal Mj \& Ali M.M. (2015). Methodology of Islamization of Human Knowledge: A Comparative Appraisal of Proposed Approaches. Arts and Social Sciences Journal. 6: $145 \mathrm{http}: / / \mathrm{dx}$. doi.org/10.4172/2151-6200.1000145

Papoutsaki, E., (2007). De-colonising journalism curricula: A research \& 'development' perspective. Paper presented at AMIC Conference, 24-17 June 2007, Singapore.

Ray, T., (2012). To de-westernize, yes, but with a critical edge: A response to Gunaratne and others. Media Culture \& Society, 34(2), 238-249.

Rosmawati Mohamad Rasit Et A1., 2011. Film as a medium of communication of da'wah: Analysis of reglisous elements in selected Malay films. Islamiyyat, 33, 67-76.

Said, E., 1979. Orientalism. New York: Vintage Book.

Semati, M., (2011). Communication, culture and the essentialized Islam. Communication Studies, 62(1), 113-126.

Siti Suriani Othman, (2012). "We just write what we think is newsy": An Analysis on Newsworthiness Constructions in Malaysian Newspapers. Unpublished PhD thesis, Nottingham Trent University, UK.

Smith, T., (2003). Decolonizing methodologies. London: Zed Books Ltd and University of Otago Press.

Syed Arabi Idid. (2014). The past and coming communication journey in Malaysia. Jurnal Komunikasi, 30, 1-16.

Tharman, K., (2003). Partnership in progress: Towards cultural democracy in teacher education. Keynote speech [online] www.atea.edu.au/confpapers/2003/Keynote\%20papers/Konai\%20Thaman.doc, accessed on 5 Oktober 2012.

Wang, G., (2011). Orientalism, Occidentalism, and communication research. In Wang, G. (ed.), De-Westernizing communication research. Oxon: Routledge.

$\mathrm{Xu}, \mathrm{X}$. (1998). Asian values revisited: In the context of intercultural news communication. Media Asia, 25, 37-41. 
Xu, X., (2005). Demystifying asian values in journalism. Singapore: Marshall Cavendish Academic.

Zaharom Nain, (2000). Globalized theories and national controls the state, the market and the Malaysian media. in CURRAN, J., \& PYUNG-JIN PARK, eds., De-westernizing media studies. London. Routledge.

Zulkiple Abd Ghani \& Mohd Safar Hasim. (2004). Islamic values and ethics in communication. Islamiyyat, 25(1), 61-69. 